\title{
Linking water and energy objectives in lowland areas through the application of model predictive control
}

\author{
P.J. van Overloop, R.R. Negenborn, S.V. Weijs, W. Malda, M.R. Bruggers, and B. De Schutter
}

\begin{abstract}
Unlike mountainous areas, lowland areas have limited potential to generate energy from water flows. Instead, for water systems in lowland areas that continuously need to pump water out of the system, the focus should be set to saving energy in the present water management. This paper gives an introduction into possibilities to manage water systems in lowland areas in a sustainable manner. An example of an energy saving method is presented that is implemented by means of model predictive control on an actual physical large pumping station in The Netherlands.
\end{abstract}

\section{INTRODUCTION}

$\mathrm{W}$ orldwide, hydropower is an important source of energy. Almost $20 \%$ of the world's electricity generation originates from hydro resources [1]. Typically hydropower is associated with large dams and reservoirs in mountainous areas for electricity generation. In mountains in countries such as Norway, China, and Brazil large dam constructions have been created to generate hydropower. On the other hand, lowland areas [2], which can be found in river deltas in countries such as The Netherlands, Belgium, and Japan are not suitable for this type of large-scale energy production. This is due to the limited head difference in the water systems. In lowland areas, dikes have been built for protection against high water levels at sea and high water flows in rivers. Due to the setting of the soil behind the dikes and the sedimentation in the delta, the inland water systems often lie lower than the surrounding waters. Therefore, water, mostly originating from precipitation, has to be pumped out of the inland water systems continuously (see Figure 1). Consequently, water management in these areas requires a considerable amount of electricity. E.g., the pumping station that is treated in this paper consumes an average of 8 million $\mathrm{kWh}$ each year.

Whereas in mountainous areas water systems have a direct link with sustainable electricity production, this link is not directly apparent in lowland areas. This paper will give an outlook on the possible and challenging link to be made between sustainability, energy and water management in

P.J. van Overloop and S.V. Weijs are with the Department of Water Management, Delft University of Technology, Delft, The Netherlands (email: \{p.j.a.t.m.vanoverloop,s.v.weijs\}@tudelft.nl).

R.R. Negenborn and B. De Schutter are with the Delft Center for Systems and Control, Delft University of Technology, Delft, The Netherlands (e-mail: \{r.r.negenborn,b.deschutter\}@tudelft.nl).

W. Malda is project manager with the New Energy department of Eneco Energie (e-mail: w.malda@eneco.nl).

M.R. Bruggers is senior advisor water and energy innovations at Deltares (e-mail: marcel.bruggers@deltares.nl) lowland areas. Note that the energy mentioned is considered to be electrical, not thermal. The most important drivers for the link are the search for a more sustainable way of dealing with water and energy and the search for possibilities to manage the water systems in a more cost-efficient way. As we will see, to achieve these goals, an enhanced management system is needed. A key technology that enables this is model predictive control (MPC), a control technique that is very well suited for this task. This advanced control method has proven its value in (chemical) process engineering and is expected to do the same in this case.

This paper is organized as follows. Section II describes the water management in lowland areas, which requires considerable amounts of energy in order to pump water out of the system. In Section III, three methods for increasing the sustainability regarding energy consumption of a system are described. Section IV projects these methods to water systems in lowland areas. Section $\mathrm{V}$ presents the implementation of one of these methods: the application of MPC for the control of a large physical pumping station in The Netherlands. In Section VI, conclusions and future research directions are given.

\section{WATER MANAGEMENT IN LOWLAND AREAS}

Figure 1 gives a schematic picture of a rural water system in a lowland area. Water management in these areas is based on drainage, where water surplus dominates over water shortage. Precipitation is intercepted and runs off or

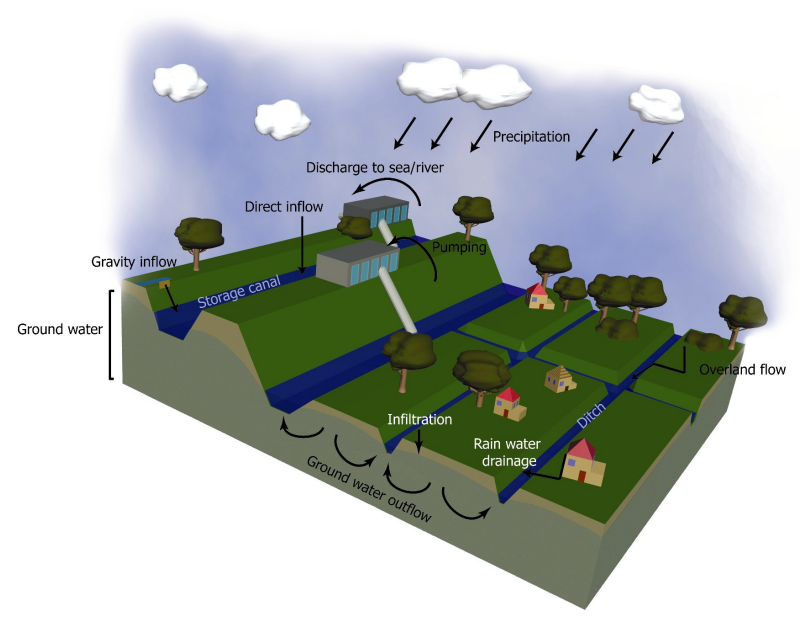

Figure 1. Schematic representation of water flows of a drainage system in a lowland area. 


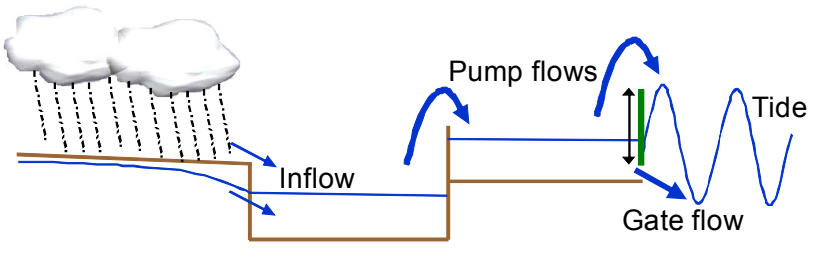

Figure 2. Schematic longitudinal profile of flows in a lowland water system.

infiltrates into the shallow ground water towards ditches. The ditches are interconnected and form a network. Usually a pump is installed in the lowest point of this water network. It is switched 'on' when the water level becomes too high and switched 'off' when enough water has left the system to reach the optimal state of the water network. These predefined switch levels lie around the desired target level (or the set-point) of the water network and form the acceptable bandwidth.

The water is pumped out of the water network into a river and flows towards the sea or is pumped into a larger canal system, as illustrated in Figure 2. This canal system discharges into sea via sluices or gates with gravity flow or with the usage of pumps when the water level at sea inhibits the necessary discharge flow. The water system is, given its drainage-based characteristic, controlled with so-called upstream feedback. In the control loop, a water level sensor is located at the upstream side of each pump and, in the controller, the sensor signal is compared with the allowed bandwidth around the set-point. When the measured water level exceeds the upper limit, the actuator receives a signal to start discharging, irrespective of the situation in the downstream water body and irrespective of the energy consumption at that specific moment. Note that here the upstream side of a pump is actually the low water level side.

\section{SUSTAINABLE ENERGY}

Sustainable energy is produced from different sources, such as the sun, the wind, biomass, and water. Typically, these sources all have their specific advantages and disadvantages. Some of the sustainable energy sources are continuously available (biomass), some with a day and night pattern (solar), others depending on the meteorological conditions (wind).

As in many countries, The Netherlands have set goals to strive for a more sustainable usage of energy. The sector responsible for water management is looking into its possibilities to contribute to the national targets. To make a transition towards a more sustainable system one can use the transition model described as Trias Energica [3]. The three elements of this approach are:

1. Reduce the demand for energy;

2. Use sustainable sources of energy;

3. Produce and use fossil energy as efficiently as possible.

\section{SUSTAINABLE WATER MANAGEMENT}

When we project the three elements of the Trias Energica on water management in lowland areas, we can state the following:

1. Energy for water management in low land water systems is typically consumed by pumps (See Section II). The demand for energy to run pumps in operational water management can be decreased by the implementation of more intelligent control systems, such as MPC [4]. MPC is able to calculate the water levels that need to be controlled using forecasts of disturbances, such as rainfall and run-off processes, and based on this compute control inputs. Together with tidal information, MPC is able to maintain water levels within acceptable bandwidths as well as to minimize energy consumption to achieve the required state of the water system. MPC uses predictions of the tides and, if possible, will wait with pumping until the water can be discharged by gravity during low tides. Furthermore, MPC can calculate the proper timing of the pumps given the relation in head-flow-power consumption of the pumps, making the pumps operate even more energy efficient. In the next section this type of MPC applied to a large pumping station is described.

2. Hydropower is considered to be a sustainable source of energy. As mentioned before, most electricity produced by water systems is generated by hydropower using dams with large water reservoirs. River deltas and lowland areas do not have large elevation drops to install dams with water reservoirs to generate electricity. Nevertheless, there are other methods to produce energy in and from the water system [5]. Such methods include hydropower from river and tidal currents and from relatively small head differences in tidal areas and at check structures in rivers. The energy production here is not based on relatively small discharges and large elevation drops, but on large discharges or large areas and small elevation drops or currents. More innovative hydropower from a salinity gradient is not regarded here, as this technique is currently not mature enough for practical implementation. The realistic potential of hydropower in rivers in The Netherlands is estimated at 80-110 MW, of which only $38 \mathrm{MW}$ is currently realized [6]. Tidal energy production in The Netherlands is estimated at several hundreds of MWs, of which none has yet been realized. Due to the distributed character of the potential energy and the aggressive, saline environment it will be a challenge to make this resource cost-beneficial.

3. Hydropower facilities with reservoirs offer unique operational flexibility in such a way that they can respond immediately to fluctuating demands for electricity. Hydropower's flexibility and storage capacity makes it one of the most efficient and cost- 
effective ways to support the deployment of intermittent renewables such as wind or solar power. The reservoirs function as a battery for energy. Water systems in river deltas, like The Netherlands, do not have large elevation drops, but do have a large storage capacity. As mentioned in Section II, water management in lowland areas requires daily operation of pumps to drain the excess volume of water out of the system. Because water levels in the lowland water systems are allowed to fluctuate within the bandwidth, the timing of pumping becomes a control variable and the water body can be employed as a battery for energy storage. To use this capacity in combination with the other objectives of the water system, advanced optimal and predictive controllers are necessary to manage this complicated task. Using this methodology, the water system can become more energy efficient and thus more sustainable, but also can contribute to a better balance in sustainable energy sources. When the economics are taken into account, one will find that using the water system as a balance for sustainable energy sources will ultimately be profitable. For example, when there is an overload of electricity on the market e.g. due to windy conditions, the water system can use this energy for pumping. In case of the opposite, the water system can postpone pumping (to a certain extent of time). In this way the water system is balancing supply and demand.

In the next section, the first method is exemplified by an implementation on a large pumping station in The Netherlands.

\section{REDUCED ENERGY DEMAND BY APPLICATION OF MPC}

Since August 2008, an MPC controller has been in operation to support the operators of the discharge complex at IJmuiden (The Netherlands) from where the North Sea Canal/Amsterdam-Rhine Canal is operated [7]. The precipitation of a catchment of approximately $2300 \mathrm{~km}^{2}$ drains into these canals and needs to be discharged into the sea. The water ways that transport the water are the Amsterdam-Rhine Canal that continues into the North Sea Canal, as illustrated in Figure 3. At the end of the North Sea Canal the water can be discharged by seven gates during low tide and by six pumps when the sea water level is higher than the canal water level. Currently, the installed pump capacity of $260 \mathrm{~m}^{3} / \mathrm{s}$ is the largest in Europe. The water levels in the (connected) canals need to be kept within a bandwidth around the set-point in order to allow for navigation and to avoid inundations.

\section{A. Setup of the MPC scheme}

The control problem can be summarized as keeping the present and (near) future water levels in the canals close to set-point and within a limited band of $25 \mathrm{~cm}$ around this set-

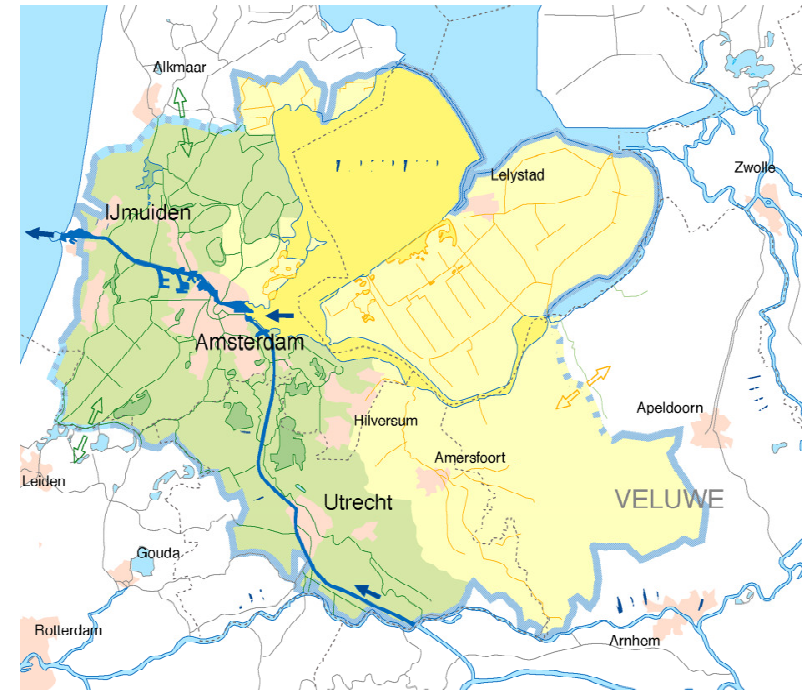

Figure 3. Map of the catchment area of Amsterdam-Rhine Canal / North Sea Canal.

point, while consuming as little energy as possible in performing this task. On top of this, the amount of gate movements needs to be minimized as well in order to minimize wear and tear. Below we detail how MPC is used to optimize the operation of the discharge complex.

\section{1) Objectives}

The main objectives in the area of IJmuiden are navigation, minimum energy consumption, and safety. The conflict in the operational management in the canal system is that navigation and safety require the water level to remain close to a target level of $-0.40 \mathrm{~m}$ with respect to mean sea level (MSL), whereas for achieving minimal energy consumption, the water level in the canal system should fluctuate: During periods with relatively a high sea water level, water should be stored in the canal, such that it can be discharged for free during low sea water level. The objective function to be minimized is therefore defined as:

$$
\begin{aligned}
J= & \sum_{k=0}^{n}\left\{W_{e} e(k)^{2}\right\} \\
& +\sum_{k=0}^{n-1}\left\{W_{\Delta Q_{g}} \Delta Q_{g}(k)^{2}+\sum_{i=1}^{6}\left\{W_{Q_{p, i}}(k) Q_{p, i}(k)\right\}\right\},
\end{aligned}
$$

where $e(k)=h_{\text {ref }}-h(k)$ is the difference between target level $h_{\text {ref }}(\mathrm{mMSL})$ and water level $h$ in the canal (mMSL), $J$ is the objective function value, $n$ is the number of steps in the prediction horizon, $W_{e}$ is the weight on the deviation $\left(\mathrm{m}^{-1}\right)$, $W_{\Delta Q \mathrm{~g}}$ is the weight on the change in discharge of all gates $\left(\mathrm{s} / \mathrm{m}^{3}\right), \Delta Q_{\mathrm{g}}$ is the change in discharge of all gates $\left(\mathrm{m}^{3} / \mathrm{s}\right)$, $W_{Q p, i}$ is the weight on the discharge of the $i^{\text {th }}$ pump $\left(\mathrm{s} / \mathrm{m}^{3}\right)$, $Q_{p, i}$ is the discharge of the $i^{\text {th }}$ pump $\left(\mathrm{m}^{3} / \mathrm{s}\right)$, and $k$ is the time step index. The weights on the discharge of each pump are time-variant and a function of the relation in head-flowpower consumption of that specific pump. 


\section{2) Prediction model for the canals}

The two interconnected canals that constitute the canal system are wide. Therefore, the canal system can be modeled as a single reservoir:

$$
h(k+1)=h(k)+\frac{Q_{d}(k) \Delta T}{A}-\frac{Q_{g}(k) \Delta T}{A}-\frac{Q_{p}(k) \Delta T}{A},
$$

where $Q_{d}$ is the disturbance inflow $\left(\mathrm{m}^{3} / \mathrm{s}\right), \Delta T$ the time step (s), $A$ the storage (surface) area $\left(\mathrm{m}^{2}\right), Q_{g}$ the summed flows through the seven gates $\left(\mathrm{m}^{3} / \mathrm{s}\right), Q_{p}$ the summed flows of all six pumps $\left(\mathrm{m}^{3} / \mathrm{s}\right)$. The time step $\Delta T$ is $600 \mathrm{~s}$.

\section{3) Constraints}

Soft constraints are applied over the prediction horizon to impose the limitation for navigation and safety:

$$
-0.55 \leq h(k) \leq-0.30 \text {. }
$$

Time-variant hard constraints over the prediction horizon are imposed on the maximum flow through all gates and the separate pumps:

$$
\begin{aligned}
& 0 \leq Q_{g}(k) \leq Q_{g, \text { max }}(k) \\
& 0 \leq Q_{p, i}(k) \leq Q_{p, i, \text { max }}(k) .
\end{aligned}
$$

These hard constraints are time variant because they depend on the predicted sea water levels and the predicted canal water levels. Obviously, when the sea water level is higher than the canal water level, $Q_{g, \max }$ is set to zero.

The predicted disturbance inflow is calculated from the measured rainfall and measured evaporation over the past 15 days (in steps of 6 hours) and from the predicted rainfall for the next 12 hours ( 2 steps of 6 hours) with an auto regressive linear model of which the calibrated parameters differ each month.

\section{4) The control scheme}

In general, using MPC, at each discrete time step $k$ an optimization problem is solved which minimizes an objective function that expresses which system behaviour and actions are desired over a certain prediction horizon in the future, taking into account a prediction model describing the behaviour of the system, possible constraints on the states, the inputs, and the outputs of the system, possible known information about future disturbances, and a measurement of the state of the system at the beginning of the time step. By solving this optimization problem the MPC controller determines those actions that give the best behaviour of the system over the prediction horizon. Once these actions have been determined, the actions for the upcoming time step are implemented. At the next time step, $k+1$, in a receding horizon fashion, a new optimization problem is formulated and solved using the most up to date information.

In our case, the optimization problem that the MPC controller solves is based on the objective function (1), the prediction model (2), and the constraints (3)-(5). As (1) is a quadratic function and (2)-(5) are linear equality and
Table 1. MPC parameters

\begin{tabular}{|l|l|}
\hline Parameter & Value \\
\hline$\Delta T$ & $600 \mathrm{~s}$ \\
\hline$A$ & $39060000 \mathrm{~m}^{2}$ \\
\hline$h_{\text {ref }}$ & $-0.40 \mathrm{mMSL}$ \\
\hline$n$ & $144 \mathrm{steps}$ \\
\hline$W_{e}$ & $100 \mathrm{~m}^{-1}$ \\
\hline$W_{\Delta Q g}$ & $0.0001 \mathrm{~s} / \mathrm{m}^{3}$ \\
\hline$W_{Q p, i}(k)$ & Ranging from 0.005 to $0.0250 \mathrm{~s} / \mathrm{m}^{3}$ \\
\hline
\end{tabular}

inequality relations, the optimization problem to be solved is a quadratic programming problem.

The MPC optimization has been implemented in a physical decision support system. In this system, a prediction horizon of $n=144$ steps, which corresponds to 24 hours, is considered. Each hour, the MPC controller performs its quadratic programming optimization, which takes less than a minute to complete. When the optimization has finished, a human operator checks the advice for the next period and accept this advice simply by clicking on an acceptance button if the operator agrees with the advice. Then, the advice for the next hour is automatically executed. Table 1 summarizes the parameters used by the MPC controller.

\section{B. Results}

\section{1) Without model predictive control}

Figure 4 shows the evolution of actual water levels, flows and energy consumption of two days in a period before the MPC controller was activated in practice.

The first graph presents the canal water level (solid line) and sea water level (dashed line). The top right graph is the power consumption. The bottom left graph presents the flow through the gates (solid line) and the disturbance inflow (dashed line), while the bottom right is the total pump flow. It can be observed that the operators maintain the water levels of the canal close to the set-point (i.e., $-0.4 \mathrm{mMSL}$ ) by
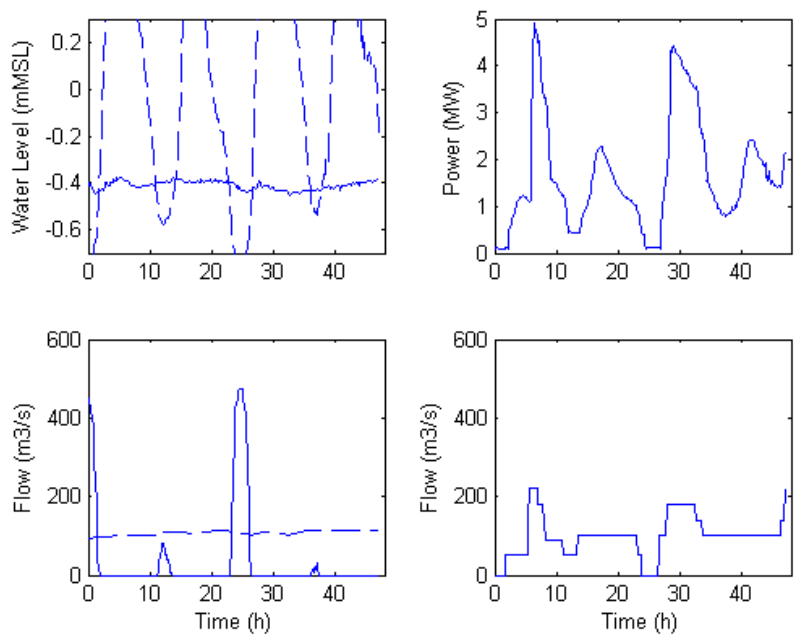

Figure 4. Evolution of water levels, flows, and energy consumption (Without MPC). 

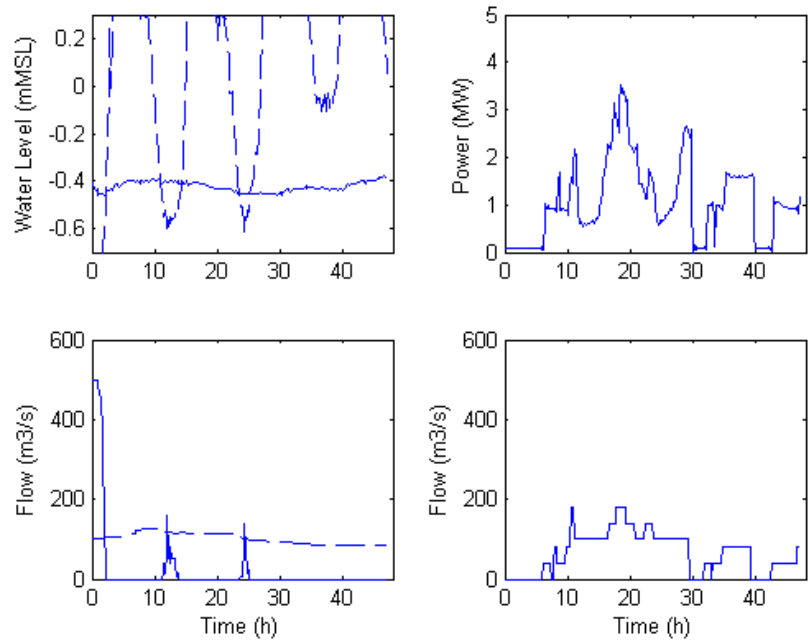

Figure 5. Result of two days with MPC.

keeping a proper number of pumps running over a long period (this can be seen from 14 to 23 hours and from 34 to 46 hours). The flow of these pumps balances the disturbance inflow. The top right graph in Figure 3 shows the energy consumption of the pumps. It can be observed that running with a constant number of pumps results in a low power use (1000 kW at hour 37) when the sea water level is low, but a power use that is 2.5 times higher $(2500 \mathrm{~kW}$ at hour 43$)$ when the sea water level is at its peak.

Even worse is the situation in which the canal water level is made lower than the set-point by discharging water for free with the gates. After the low tide, the operator stops discharging water, but is triggered again to start discharging when the water level becomes higher than the set-point (at hour 6 hours on the first day). By starting multiple pumps, the canal water level is kept at the set-point. The timing however is costly as the starting of the pumps coincides with the peak sea water level.

The total amount of energy consumption over two days is $79.5 \mathrm{kWh}$ and the peak power usage is $4956 \mathrm{~kW}$.

\section{2) With model predictive control}

Two other days are selected after the MPC controller has been put into operation. This period has approximately the same inflow volume and potential gravity (gates) discharge volume compared to the previously described days at which the MPC controller was not used. As can be observed in Figure 5, the result of the controller is such that the canal water level fluctuates slightly more, but is still within the allowed band. The pumps switch approximately twice as often in order to achieve the most cost-effective usage. However, the energy consumption is $54.5 \mathrm{kWh}$ and the peak power is $3528 \mathrm{~kW}$. This corresponds to a reduction of $34 \%$ in costs compared to the case without MPC. For other situations average cost reductions over a year in the order of $20 \%$ were computed. The average energy costs for operating the pumps over the past five years (2003 to 2007) has been almost 1 million euro per year. Hence, using MPC can result in a cost reduction of 200000 euro per year.

\section{CONCLUSIONS AND RECOMMENDATIONS}

Due to the limited land elevation drop in lowland areas, it is hard to generate significant amounts of energy from hydropower. On the other hand, there can be a strong link between energy and water, which offers opportunities to reach a more sustainable management of the water flows. First of all, water management in lowland areas can be made much more energy-efficient when advanced predictive controllers become part of the operation of pumping stations. This has been shown in an actual implementation of an MPC controller on a large pumping station in The Netherlands. Secondly, as water management requires vast amounts of energy over the day while the actual timing of this energy demand is less important, there are possibilities to link energy networks and water networks. Water bodies that may fluctuate over the day can function as batteries that can dampen peak demands and use up temporal over-capacity. Future research will explicitly focus on this link. A first step will be to incorporate fluctuating rates for energy consumption (e.g. day and night rates). Another way by which we expect to increase the efficiency is by incorporating multiple water systems that coordinate their objectives and constraints using distributed MPC $[8,9]$.

\section{ACKNOWLEDGEMENT}

This research is supported by the BSIK project "Next Generation Infrastructures (NGI)", the Delft Research Center Next Generation Infrastructures, and the European STREP project "Hierarchical and distributed model predictive control (HD-MPC)".

\section{REFERENCES}

[1] International Hydropower Association, Hydropower and Sustainability, http://www.hydropower.org/.

[2] Ven, G.P. van de, Man-made Lowlands. History of Water Management and Land Reclamation in The Netherlands, Matrijs, Utrecht, The Netherlands, 2004.

[3] Lysen, E.H., The Trias Energica: Solar Energy Strategies for Developing Countries, Proceedings of the Eurosun Conference, Freiburg, September 1996.

[4] Camacho, E.F., C. Bordons, Model Predictive Control, Springer, New York, 1999.

[5] Jong, R.J. de, N. Slootjes, T. van den Noortgaete, Potentie duurzame energie bij kunstwerken, WINN Energie uit Water, Deltares, 2009. In Dutch.

[6] SenterNovem, Hydropower project (G6), http://www.senternovem .nl/greenfundsscheme/project_categories/renewable_energy/.

[7] Overloop, P.J. van, Model Predictive Control on Open Water Systems, PhD thesis, Delft University of Technology, The Netherlands, 2006.

[8] Negenborn, R.R., P.J. van Overloop, T. Keviczky, B. De Schutter, Distributed model predictive control for irrigation canals, Networks and Heterogeneous Media, vol. 4, no. 2, pp. 359-380, June 2009.

[9] Overloop, P.J. van, R.R. Negenborn, B. De Schutter, N.C. van de Giesen, Predictive Control for National Water Flow Optimization in The Netherlands, Intelligent Infrastructures (R.R. Negenborn, Z. Lukszo, H. Hellendoorn, eds.), Springer, Dordrecht, The Netherlands, pp. 439-461, 2010 